\title{
Review Article \\ Pharmacological Protection of Kidney Grafts from Cold Perfusion-Induced Injury
}

\author{
Anna Krzywonos-Zawadzka, ${ }^{1}$ Aleksandra Franczak $\left(\mathbb{D},{ }^{1}\right.$ Michael A. J. Moser, ${ }^{2,3}$ \\ Agnieszka Olejnik $\left(10,{ }^{1}\right.$ Grzegorz Sawicki $\left(\mathbb{C}^{1,4}\right.$ and Iwona Bil-Lula ${ }^{1}{ }^{1}$ \\ ${ }^{1}$ Department of Medical Laboratory Diagnostics, Division of Clinical Chemistry, Wroclaw Medical University, \\ Ul. Borowska 211A, 50-556 Wroclaw, Poland \\ ${ }^{2}$ Department of Surgery, University of Saskatchewan, Saskatoon, SK, Canada \\ ${ }^{3}$ Saskatchewan Renal Transplant Program, Saskatoon, SK, Canada \\ ${ }^{4}$ Department of Pharmacology, College of Medicine, University of Saskatchewan, Saskatoon, Canada
}

Correspondence should be addressed to Iwona Bil-Lula; iwona.bil-lula@umed.wroc.pl

Received 14 December 2018; Revised 26 April 2019; Accepted 30 April 2019; Published 14 May 2019

Academic Editor: Hartmut Jaeschke

Copyright (C) 2019 Anna Krzywonos-Zawadzka et al. This is an open access article distributed under the Creative Commons Attribution License, which permits unrestricted use, distribution, and reproduction in any medium, provided the original work is properly cited.

\begin{abstract}
One of the greatest challenges facing the field of organ transplantation is the shortage of donor organs for transplantation. Renal transplantation increases quality of life and survival of patients suffering from end-stage renal disease. Although kidney transplantation has evolved greatly over the past few decades, a not insignificant amount of injury occurs to the kidney during recovery, preservation, and implantation and leads to the loss of function and loss of years of dialysis-free living for many patients. The use of kidneys from expanded criteria donors (ECD) and donation after circulatory determination of death (DCDD) has been adopted partly in response to the shortage of donor kidneys; however these kidneys are even more susceptible to ischemic injury. It has been shown that matrix metalloproteinases (MMPs) and reactive oxygen species (ROS) are involved in mechanisms of injury to the transplant kidney. There is also some evidence that inhibition of MMP activity and/or ROS production can protect the kidney from injury. We review possible pharmacological strategies for protection of kidney graft from injury during recovery, preservation, and implantation.
\end{abstract}

\section{Introduction and Background}

Kidney transplantation increases quality of life and life expectancy in patients suffering from end-stage renal disease compared to renal dialysis. In an effort to increase the number of kidneys available for transplantation in the face of ongoing donor organ shortage, the use of kidneys from more marginal donors has been increasing. This includes kidneys from older donors and those with cardiovascular diseases, such as hypertension (expanded criteria donors (ECD)), as well as donation after circulatory determination of death (DCDD). Both ECD and DCDD kidneys are associated with poorer initial function, a higher rate of delayed graft function (DGF) and poorer function at one year after transplantation [1]. Furthermore, it has been suggested that DGF and kidney injury of any kind are associated with an increased risk of acute rejection [2].

Although kidney transplantation has evolved greatly over the past few decades, the fact remains that, in the process of removing a kidney from a donor, flushing, and cooling it, then rapidly rewarming it once its blood vessels are connected in the recipient, significant injury occurs to the kidney and leads to loss of function as well as loss of years of dialysis-free living of these patients.

Ischemia-reperfusion injury (IRI) is an inevitable relevant outcome of kidney transplantation. Kidneys from DCDD are highly sensitive to IRI, a complex pathophysiological process involving hypoxia and following reoxygenation, ionic imbalance, oxidative stress, and mitochondrial uncoupling, as well as a coagulation and endothelium activation 
associated with a proinflammatory immune response. The main consequences of renal IRI are kidney graft primary nonfunction and delayed graft function or chronic graft dysfunction, all of which involve a mandatory patient's return to dialysis. The incidence of delayed graft function varies greatly, ranging from $10 \%$ when using living donor kidneys to more than $50 \%$ for DCDD kidneys [3]. In addition, the DGF is one of the more frequent early complications after the deceased-donor kidney transplantation and is primarily a consequence of postischemic acute tubular necrosis caused by IRI [4].

Minimizing kidney injury would be a tremendous benefit to patients who are waiting for kidney transplant. By potentially broadening the pool of kidneys that could be acceptable for transplantation purposes, the optimization of kidney preservation and reduction of injury is of great importance in kidney transplantation.

\section{The Three Phases of Transplantation during Which Injury Can Occur}

During the process of transplantation from one person to another, the kidneys are subjected to ischemic injury, when the blood flow supply is either interrupted or severely disturbed as well as reperfusion injury become as a consequence of the blood flow reconstruction. Injury occurs first time during the procurement (warm ischemia time, WIT I and WIT II), then a second time during the preservation (cold ischemia time, CIT), and a third time at the time of reperfusion and reoxygenation.

Warm ischemic time lasts from stopping of blood flow through the donor organ until cold perfusion is commenced (WIT I). WIT I differs regarding type of donors: it lasts just a few minutes for living donors, much longer for DCDD donors and it is minimal for donation after neurological determination of death (DNDD) donor kidneys. A period of relative ischemia between withdrawal of life supporting treatments and asystole can last from a few minutes to one and a half hours or even 2 hours depending on the program and factors specific to each DCDD donor. Prolonged time of warm ischemia in DCDD leads to greater damage of transplanted kidney compared to donation after brain death (DBD) with all the consequences: poorer initial as well as long-term functions, DGF, and higher risk of rejection [12, 13]. This emphasizes the need for strategies to minimize WIT.

WIT II relates to vascular anastomosis (from removal of the organ from ice until reperfusion in recipient) [14] and this type of injury may be reduced by faster anastomosis or keeping the kidney cool during anastomosis using Ice Bag Technique [14].

Cold ischemia time also has an impact on the graft outcome after transplantation. Prolongation of CIT may predispose to DGF and lead to reduced graft survival and even patient survival $[15,16]$. Unfortunately, a significant decrease in CIT might be difficult because of logistics (transport; procedure time).

Static cold storage in which the preservation solution is infused into the organ to flush out the blood and then the organ is immersed in the preservation solution for storage remains the most often used method for kidney preservation. Numerous preservation solutions have been developed to prevent the biochemical and structural changes that occur during the process of graft cooling and reperfusion. However, the amount of time that ECD or DCDD kidneys can be safely preserved in this manner remains limited, highlighting the need for novel strategies to improve kidney preservation and recovery [17].

Machine cold perfusion allows preservation solution to circulate continuously through the kidney for 4 to 48 hours (via the artery). Machine cold perfusion of transplant kidneys has shown benefit in terms of both early and long-term function [17] and this benefit may be even greater in more marginal kidneys from ECD and those obtained from DCDD [18]. However, kidney injury still occurs even when machine cold perfusion is used [6]. The mechanism by which machine perfusion protects the kidney from injury is unknown; however, it has been hypothesized that it may allow continual flushing of the microcirculation, prevent the accumulation of waste products, or reduce free radical formation [19]. Regardless, the 4 to 36 or more hours' period when a kidney is "on the pump" seems to be a strategic time for pharmacological interventions to help in protecting the kidney from IRI.

\section{The Mechanism of Kidney Ischemia-Reperfusion Injury during the Process of Transplantation}

IRI is a multifactorial process that occurs when the blood supply to an organ is impaired followed by restoration of blood flow and reoxygenation. IRI has been described in vascular and cardiac surgery, trauma, and circulatory arrest with resuscitation and kidney transplantation.

The main factors contributing to kidney's damage during IRI are (a) oxidative stress, (b) accumulation of calcium in the cytosol, (c) mitochondrial uncoupling, and (d) a release of iron ions and inflammatory immune response (Figure 1).

(A) Ischemia leads to an increase of anaerobic metabolism, accumulation of metabolic waste products, and reduction in adenosine triphosphate (ATP) concentration, while reperfusion results in reoxygenation, and a return to aerobic metabolism. The disorders triggered during ischemia cause injury or death of tubular epithelial cells and the following reperfusion further enhances this damage as large amount of deleterious reactive oxygen species is generated [20]. ROS are toxic, highly reactive, and unstable molecules formed during a variety of normal and pathological biochemical conditions leading to DNA damage, mitochondrial malfunction, cell membrane damage, and cell death (a phenomenon referred to as "oxidative stress").

(B) Prolonged ischemia increases metabolic demand and energy failure. As a consequence of anaerobic metabolism, decrease in cell $\mathrm{pH}$ is observed. Progressive depletion of ATP leads to inactivation of $\mathrm{Na}^{+} / \mathrm{K}^{+}$ 
ISCHEMIA

\section{REPERFUSION}
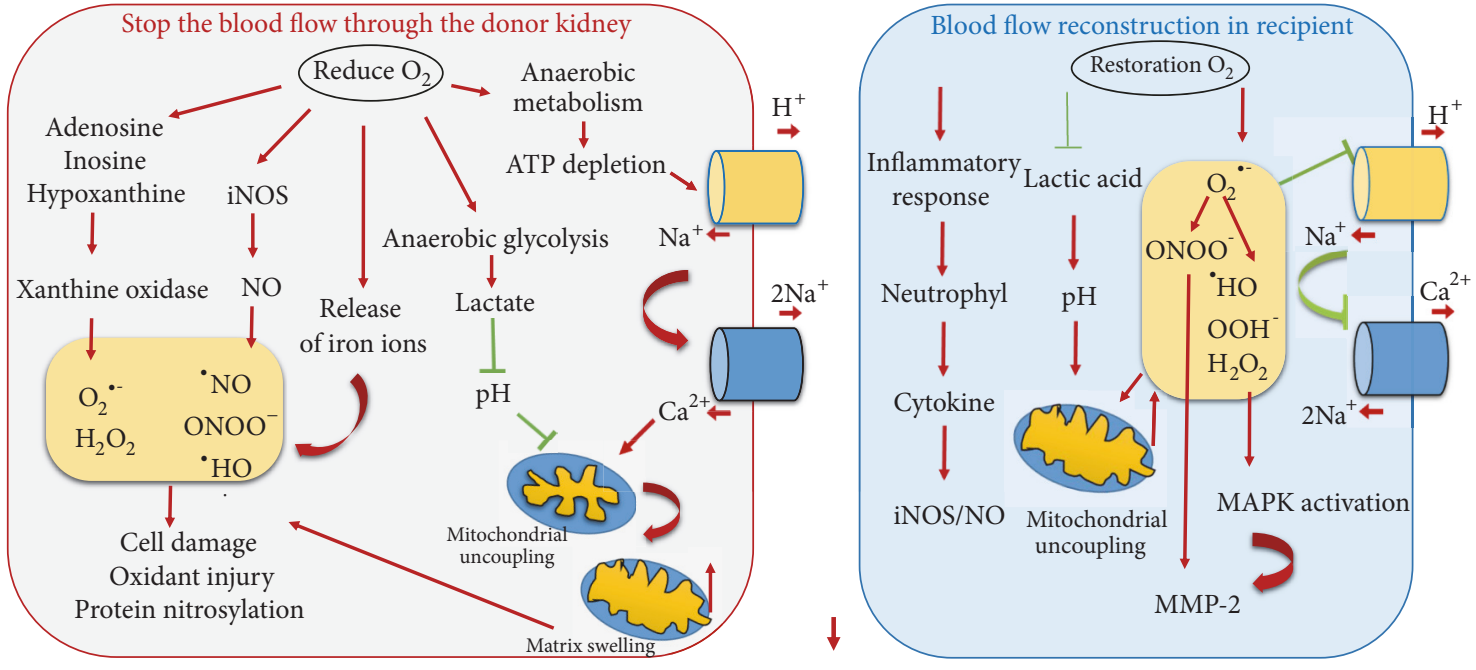

Poorer initial function

Poorer long-term function DGF

Tubular atrophy

Higher risk of rejection $\longrightarrow$ decrease

$\rightarrow$ increase (a)

\section{ISCHEMIA}

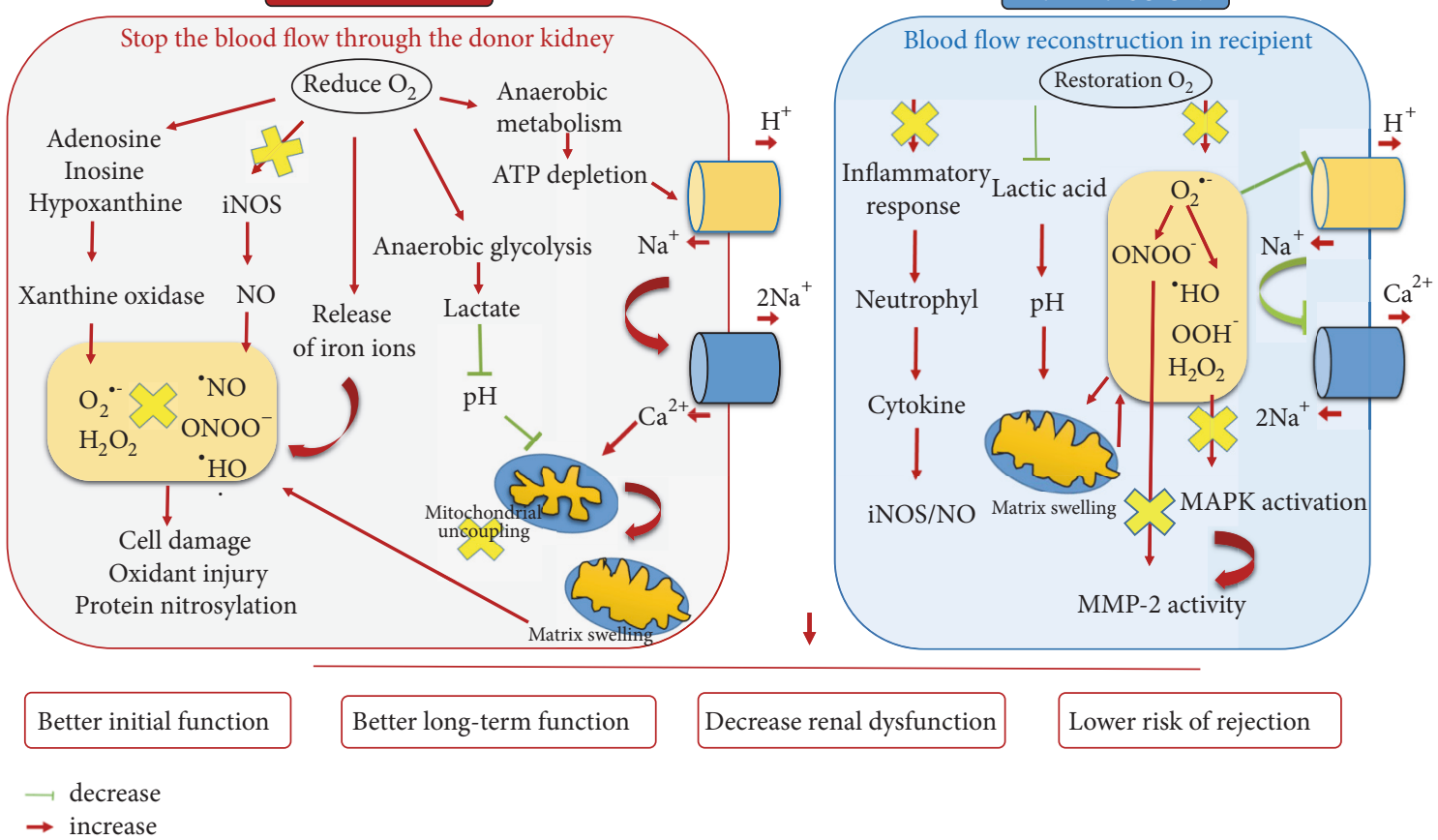

(b)

FIGURE 1: (a) Mechanisms of renal ischemia-reperfusion injury. The main factors contributing to kidney's damage during IRI are oxidative stress and iNOS production, a release of iron ions, accumulation of calcium in the cytosol, mitochondrial uncoupling, and inflammatory immune response. Arrows mark the increase effect $(\longrightarrow)$; dash terminated with line means a decrease $(\vdash)$. (b) Potential pathways of the pharmacological protection of kidney graft from ischemia-reperfusion injury. Administration of free radical scavengers, inhibitors of iNOS and MMPs activity, or gasotransmitters are proposed to be a strategy for attenuating renal I/R injury. Yellow mark (x) indicates a potential therapy goal. DGF: delayed graft function; ATP: adenosine triphosphate; MMP-2: matrix metalloproteinase-2; $\mathrm{O}_{2}{ }^{--}$: superoxide radical anion; $\mathrm{H}_{2} \mathrm{O}_{2}$ : hydrogen peroxide; 'HO: hydroxyl radical; $\mathrm{OOH}$ : perhydroxyl radical; iNOS: inducible $\mathrm{NO}$ synthase; $\mathrm{ONOO}^{-}$: peroxynitrite; NO: nitric oxide. 
ATPase and accumulation of its metabolites: adenosine, inosine, and hypoxanthine. Under nonischemic conditions, the latter one is a substrate of xanthine dehydrogenase but ionic imbalance during ischemia causes a calcium-triggered proteolytic conversion of xanthine dehydrogenase to xanthine oxidase which at the moment of reperfusion generates the superoxide free radical $\left(\mathrm{O}_{2}{ }^{\cdot-}\right)$ as a by-product of its action. Superoxide free radical generates secondary, more toxic reactive oxygen species: hydrogen peroxide $\left(\mathrm{H}_{2} \mathrm{O}_{2}\right)$ and hydroxyl radical $\left({ }^{\circ} \mathrm{HO}\right)$ [21]. Furthermore, a conformational change in endothelial cells during IRI leads to the release of iron ions which are substrates or catalysts in Fenton and Haber-Weiss reactions [22].

(C) Mitochondria also play an important role in the cascade of organs' damage as a result of ischemiareperfusion. An increase of membrane permeability and thus calcium overload in the cell are observed. That triggers in turn the reduction of mitochondrial membrane potential and further inhibition of oxidative phosphorylation by impaired ATP production [23].

(D) Finally, ischemia-reperfusion injury is associated with neutrophil infiltration. Leukocytes mediate microvascular injury by release of proteolytic enzymes and reactive oxygen species generation. Moreover peroxynitrite, which has strong oxidizing properties, is generated during IRI. It is an additional agent triggering damage of molecules in cells including DNA and proteins [24].

All above-mentioned factors contribute to necrosis or apoptosis of tubular epithelial cells. As renal tubular atrophy occurs, progressive deterioration of kidney graft function is observed [24].

\section{The Role of MMPs in Kidney Transplant Injury}

Matrix metalloproteinases (MMPs) are a family of more than 25 structurally related proteolytic enzymes, which play important roles in a variety of physiological processes, including morphogenesis, cartilage and bone repair, wound healing, cell migration, and angiogenesis [25]. The best known MMPs are MMP-2 and MMP-9 (gelatinases) which are found in almost all cell types; they degrade and remodel collagens and other extracellular matrix proteins. Some previous studies revealed that MMPs act not only in the extracellular matrix but also at the cellular level [26].

MMPs activity is regulated at multiple levels including transcription, modulation of mRNA half-life, secretion, localization, activation, and suppression by specific and nonspecific proteinase inhibitors [26]. They are expressed as latent enzymes and can be activated by proteolytic cleavage of the N-terminal propeptide in the pericellular and extracellular compartments by a membrane-type MMPs (MTMMP) [27, 28]. The proteolytic removal of the propeptide region perturbs the binding of a key cysteine thiol residue with the active $\mathrm{Zn}$ site. The disruption of this Cys$\mathrm{Zn}^{2+}$ bond can be induced by ROS, such as peroxynitrite $\left(\mathrm{ONOO}^{-}\right)$and its derivatives. MMPs might be also regulated by naturally occurring protein inhibitors (tissue inhibitors of metalloproteinases, TIMPs) [29]. Among synthetic inhibitors of MMPs there are o-phenanthroline, hydroxamates, and tetracycline-class of antibiotics (of which doxycycline is the most potent). They all share the common characteristic of having high specificity in chelating $\mathrm{Zn}^{2+}$ [30]. However, they are nonselective MMPs inhibitors. As an alternative, commercially available small interfering RNA (siRNA) can be used to suppress the expression of specific genes at the mRNA level [31]. Many different siRNAs have been developed to inhibit lots of genes, also including gene for MMP-2 and MMP-9.

MMPs have long been implicated in fibrotic renal diseases. MMP-2 is involved in renal ischemia-reperfusion injury in an animal model whereby warm ischemia was induced on MMP-2 deficient transgenic mouse model [5]. The degree of acute tubular injury, necrosis, apoptosis, and renal dysfunction was markedly less in the MMP-2 deficient transgenic mice compared to that seen in the wild type mice.

MMPs play an important role in the injury of the transplanted kidney as well. Since MMPs are increased in patients with chronic antibody mediated rejection and in the fibrotic renal diseases, MMPs have been suggested to be a common pathway for chronic allograft nephropathy in the transplanted kidney [32]. On the basis of recent study showing that specific inhibition of MMPs plays a cardioprotective role during IR injury it is possible that MMPs inhibitors might have a similar protective effect on the IR damage that occurs in kidney being reoxygenated after transplantation and machine cold perfusion [33]. The use of the ex vivo rat model of cold perfusion confirmed that doxycycline protects the kidney from injury during cold preservation [6]. What is more, MMPs are indeed found in the perfusate of human transplant kidneys [6], supporting a possible significant role of MMPs in the injury that occurs to kidneys during cold preservation, in keeping with prior studies of fibrotic renal diseases, renal ischemia-reperfusion injury, and chronic kidney rejection (Table 1). In conclusion, it has been shown that inhibition of MMPs may be a novel strategy for protection of the transplant kidney. The addition of pharmacological agents, as doxycycline, during preservation might reduce the damage of the kidneys [6].

\section{Oxidative Stress during Renal Ischemia and Reperfusion}

During ischemia, cell swelling caused by ATP depletion increases the osmotic gradient that drives water into the mitochondrial matrix to causes matrix swelling [7]. Thirty minutes of renal ischemia in rats increases matrix volume threefold and causes unfolding of cristae membranes. The loss of cristae membranes inhibits mitochondrial respiration and slows down the recovery of ATP synthesis upon reperfusion. Furthermore, electron leak in the mitochondrial electron transport chain is a major source of ROS after ischemia [7]. 
TABLE 1: Pharmacological strategies in the prevention of kidney ischemia-reperfusion.

\begin{tabular}{|c|c|c|c|c|c|c|c|}
\hline Study & Species & Model & $\begin{array}{l}\text { Ischemia } \\
\text { (min) }\end{array}$ & Reperfusion & Inhibitor & Dose & $\begin{array}{c}\text { Effect on } \\
\text { kidney function } \\
\end{array}$ \\
\hline [5] & $\begin{array}{l}\text { Knockout } \\
\text { MMP-2 } 2^{-/-} \\
\text {mice }\end{array}$ & In vivo & 60 & $24 \mathrm{~h}$ & Minocycline & $45 \mathrm{mg} / \mathrm{kg}$ & $\begin{array}{c}\downarrow \text { ATI } \\
\downarrow \text { Renal dysfunction }\end{array}$ \\
\hline [5] & $\begin{array}{l}\text { Knockout } \\
\text { MMP-2 } 2^{-/-} \\
\text {mice }\end{array}$ & In vivo & 60 & $24 \mathrm{~h}$ & $\begin{array}{c}\text { MMP- } \\
\text { 2/MMP-9 } \\
\text { Inhibitor III }\end{array}$ & $2.5 \mathrm{mg} / \mathrm{kg}$ & $\begin{array}{c}\downarrow \text { ATI } \\
\downarrow \text { Renal dysfunction }\end{array}$ \\
\hline [6] & Rat & In vivo & 10 & - & Doxy & $100 \mu \mathrm{M}$ & $\begin{array}{c}\downarrow \mathrm{LDH} \\
\downarrow \mathrm{NGAL} \\
\downarrow \text { Cco }\end{array}$ \\
\hline [6] & Rat & In vivo & 10 & - & $\begin{array}{l}\text { MMP-2 } \\
\text { siRNA }\end{array}$ & $10 \mu \mathrm{M}$ & $\begin{array}{c}\downarrow \mathrm{LDH} \\
\downarrow \mathrm{NGAL} \\
\downarrow \mathrm{CcO}\end{array}$ \\
\hline [7] & Rat & In vivo & 45 & $4 w k$ & SS-20 & $2 \mathrm{mg} / \mathrm{kg}$ & $\begin{array}{c}\downarrow \text { Cytoskeletal } \\
\text { breakdown } \\
\downarrow \text { Mitochondria } \\
\text { matrix swelling }\end{array}$ \\
\hline [8] & Rat & In vivo & 60 & $6 \mathrm{~h}$ & Taurine & $200 \mathrm{mg} / \mathrm{kg}$ & $\begin{array}{c}\downarrow \text { Degeneration } \\
\text { tubular } \\
\text { architecture } \\
\downarrow \text { Inflammatory cell } \\
\text { infiltration } \\
\downarrow \text { Renal dysfunction }\end{array}$ \\
\hline [9] & Mice & In Vivo & 45 & Up to 7 days & Everolimus & $0.25 \mathrm{mg} / \mathrm{kg}$ & $\begin{array}{l}\downarrow \text { Kidney function } \\
\downarrow \text { Recovery of kidney } \\
\text { function }\end{array}$ \\
\hline [10] & Pig & In vivo & 25 & $18 \mathrm{~h}$ & $1400 \mathrm{~W}$ & $10 \mathrm{mg} / \mathrm{kg}$ & $\begin{array}{l}\uparrow \text { Renal function } \\
\downarrow \text { Oxidative stress }\end{array}$ \\
\hline [11] & Mice & In Vivo & 45 & Up to $24 \mathrm{~h}$ & MitoQ & $4 \mathrm{mg} / \mathrm{kg}$ & $\downarrow$ Oxidative damage \\
\hline
\end{tabular}

SS-20: H-Phe-D-Arg-Phe-Lys- $\mathrm{NH}_{2}$; Taurine: 2-aminoethanesulfonic acid; Everolimus: RAD001; DOXY: doxycycline; wk: weeks; $\uparrow:$ increased; $\downarrow$ : decreased.

Oxidative stress results from an imbalance between the formation and the neutralization of prooxidants, such as superoxide radical anion $\left(\mathrm{O}_{2}{ }^{--}\right)$and hydroxyl radical $\left(\mathrm{HO}^{*}\right)$ and certain nonradicals that either are oxidizing agents or are easily converted into radicals, such as hydrogen peroxide $\left(\mathrm{H}_{2} \mathrm{O}_{2}\right)$ and hypochlorous acid ( $\left.\mathrm{HOCl}\right)$. ROS generation triggers a cascade of reactions starting with the production of $\mathrm{O}_{2}{ }^{--}$which can be further converted to $\mathrm{H}_{2} \mathrm{O}_{2}$ by superoxide dismutases (SOD), manganese superoxide dismutase (MnSOD) in mitochondria, and copper-zinc superoxide dismutase (CuZnSOD) in cytosol. The main sinks for $\mathrm{H}_{2} \mathrm{O}_{2}$ are catalase (CAT) and glutathione peroxidase (GPx). The latter uses glutathione (GSH) which is oxidized to GSSG and recycled by glutathione reductase. There are other enzymes that can remove $\mathrm{H}_{2} \mathrm{O}_{2}$, such as peroxiredoxin/thioredoxin/thioredoxin reductase (Prx/Trx/TrxR) system. However, CAT activity is about three orders of magnitude higher compared to $\operatorname{Prx} / \operatorname{Trx} / \operatorname{TrxR}$ system which is essential under physiological settings for keeping low levels of mitochondrial $\mathrm{H}_{2} \mathrm{O}_{2}$ emission and for normal redox signaling via regulation of thiol redox switches on different proteins [34].

Increased ROS production causes activation of p38 mitogen-activated protein kinase (MAPK) signaling which participates in gene regulation of MMPs, especially MMP2 and MMP-9 [35]. It was recently investigated that a free radical scavenger: 2 -aminoethanesulfonic acid (taurine), through p38 MAPK signaling, plays a protective role in regulation of MMP-2 and MMP-9 activity in a renal I/R injury (animal model) [8]. For this reason, administration of free radical scavengers could be a strategy for attenuating renal $I / R$ injury (regarding both oxidative stress and MMPs activity).

Besides ROS, reactive nitrogen species (RNS), such as nitric oxide $\left(\mathrm{NO}^{\circ}\right)$ and peroxynitrite $\left(\mathrm{ONOO}^{-}\right)$, are produced in kidney IRI by inducible NO synthase (iNOS) in tubule cells. Its activity leads to producing $\mathrm{NO}$ in high concentration. Then, $\mathrm{NO}$ rapidly interacts with $\mathrm{O}_{2}^{--}$to form $\mathrm{ONOO}^{-}$which trigger cell damage, oxidant injury, and protein nitrosylation [36]. Numerous experimental studies have shown an increased NOS activity in kidney IRI [9]. The production of 
NO is important for maintaining a variety of physiological functions within the kidney as well as other solid organs. Physiologic concentrations of NO in kidney act as a tonic vasodilator but higher concentrations can be toxic, damaging cellular constituents (such as DNA) and inducing hypotension. The contributions of nitric oxide were examined in ischemia-reperfusion injury in the rat kidney. After addition of NOS inhibitors kidneys had improved renal function and reduced oxidative stress [10] (Table 1). Additionally, NOS inhibitors were documented to reduce ischemia-reperfusion injury in kidney model of DCD donor [10]. What is more, ROS significantly contribute to the rewarming injury that occurs to the transplant kidney once its blood vessels are connected in the recipient (reoxygenation).

Hence due to increased ROS/RNS production over the course of cold preservation and reoxygenation the inhibition of $\mathrm{H}_{2} \mathrm{O}_{2}, \mathrm{ONOO}^{-}$, and $\mathrm{NO}$ production might be able to protect the kidney from I/R injury during transplantation as it was shown on ischemic heart studies [37]. Studies on $\mathrm{I} / \mathrm{R}$ heart model has shown that oxidative stress injury is caused by I/R, infusion of $\mathrm{ONOO}^{-}$or cytokines into the myocardium increases the activity of MMP-2. This activity is positively correlated with the degree of injury. A promising new advance is the protective effect of potent scavengers of free radicals and inhibitors of lipid peroxidation administered at the time of reperfusion in a rat model of ischemic AKI. Several scavengers of ROS (e.g., superoxide dismutase, catalase, $\mathrm{N}$-acetylcysteine, and edaravone) have been shown to protect against ischemic AKI in animals, but human studies have been inconclusive [36].

The relatively unsatisfactory efficiency of conventional antioxidants may be the consequence of their low penetrance to the mitochondria interior, which suffer from oxidative stress as other cellular compartments. The inner mitochondrial membrane is highly impermeable and rich in cardiolipin and maintains a strong negative internal potential that is required for the function of electron transport chain [38]. To overcome these limitations, mitochondria-targeted antioxidants have been developed to provide their delivery to the mitochondrion interior. Mitochondria-targeted antioxidants are usually chimeric molecules of a cation triphenylphosphonium (TPP) conjugated with an antioxidant moiety such as coenzyme Q10 or plastoquinone; hence, the drug concentration achieved in the mitochondrial matrix is 10,000 times higher than in the cytosol [39]. Mitochondria-targeted antioxidants have been already used in several experimental models where mitochondrial oxidative damage underlies them. One of the antioxidants, mitoquinone mesylate, has been used in phase II trials in humans regarding treatment of Parkinson disease and chronic hepatitis $\mathrm{C}$ showing long-term safety and tolerance [40]. Also, a targeting an antioxidant to mitochondria results in decreasing cardiac ischemia-reperfusion injury [41]. Mitoquinone mesylate, as a positively charged lipophilic cation, is accumulated in the negatively charged interior of mitochondria. Ubiquinone antioxidant component of mitoquinone mesylate is also found in coenzyme Q10. By the action of the enzyme Complex II in the mitochondrial respiratory chain, ubiquinone part of mitoquinone mesylate is rapidly activated to the active ubiquinol antioxidant. After detoxifying ROS, the ubiquinol part of mitoquinone mesylate is converted to ubiquinone, which is again subjected to Complex II to be recycled back to active antioxidant ubiquinol. This process makes mitoquinone mesylate an effective mitochondria-targeted antioxidant able to decrease heart and hepatic IRI [11]. Thus, mitoquinone mesylate added to preservation solution might prevent kidney damage during cold storage.

To effectively improve clinical outcomes of kidney transplant, gasotransmitters has recently been identified as a potential therapeutic strategy to minimize renal IRI during transplantation [42]. Gasotransmitters are the family of endogenously produced gaseous molecules that exhibits numerous antiapoptotic, antioxidant, and anti-inflammatory features that decrease IRI-associated apoptosis, oxidative stress, and inflammation, respectively. The gasotransmitters family is represented by nitric oxide, carbon monoxide, and hydrogen sulfide. Treatment of kidney donors with carbon monoxide releasing molecules (CORM-3) increases frequency of live cells and reduces cellular and graft injury through its tubular antiapoptotic effects and by upregulation of mitochondrial related Bcl-2 survival factors [43]. It has been reported that supplementation of CORM-3 at the stage of initial ischemic injury and before cold storage exposure markedly improved graft survival in models of heart and kidney transplantation. CORM-3 was identified to be protective against IRI through the reactive oxygen species upregulation and decreasing endothelial inflammation [43]. Similar effects were observed with hydrogen sulfide $\left(\mathrm{H}_{2} \mathrm{~S}\right)$ treatment. Supplementation of standard organ preservation solution with $\mathrm{H}_{2} \mathrm{~S}$ decreased the severity of graft injury associated with prolonged cold ischemia time in rat models of kidney transplantation. $\mathrm{H}_{2} \mathrm{~S}$ significantly reduced the graft inflammation, expression of proinflammatory markers and progression of tissue necrosis compared to kidneys stored in standard solution. Additionally, $\mathrm{H}_{2} \mathrm{~S}$ limits renal cellular oxidative damage through preservation of mitochondrial membrane integrity [44]. To sum up, treatment of donor kidneys with gasotransmitters $\left(\mathrm{H}_{2} \mathrm{~S}\right.$ or CORM-3) during prolonged cold storage might improve survival and recovery of allograft function during the acute posttransplant period.

\section{Conclusion}

Renal injury during the process of transplantation is a complex issue which has become an important topic in transplantation research in recent years. The shortage of donor organs has necessitated the use of kidneys from marginal donors such as DCDD and ECD donors. However, these organs are more sensitive to injury and DCDD or ECD transplantations result in inferior outcomes compared with living donor kidneys and DNDD kidneys. Therefore, the ability to minimize of graft injury would be a tremendous benefit to patients who are waiting for a kidney transplant by helping with initial function, by potentially increasing the longevity of kidney transplants, and by broadening the donor pool of kidneys that could be acceptable for transplant purposes. In the case of ECD and DCDD donor kidneys, the 
optimization and reduction of WIT and CIT have become an important topic in transplantation.

Machine cold perfusion of transplant kidneys has shown benefits in terms of both early and long-term function of the organ [17]. The use of doxycycline, hydrogen sulfide, or carbon monoxide releasing molecules is showing promise in the reduction of injury and the time that a kidney is on the machine perfusion apparatus is an opportunity for pharmacological treatment and prevention of graft injury. A combination approach may lead to additive protective effects through the prevention of injury through different mechanisms.

Oxidative stress is an element of the cascade of processes participating in IRI. What is more, an excessive production of ROS and RNS not only directly participates in tissue damage but also has an influence on MMPs activity [8]. The oxidative stress leads to posttranslational modifications of different proteins which make them substrates for MMPs [45]. Many researchers have documented the role of MMPs in ischemic damage in the heart, but the basic molecular and cellular mechanisms of all IRI are similar throughout the body. The MMPs' contribution to preservation injury was confirmed in study where it was observed that the amount of MMP-2 and MMP-9 in the perfusates from human kidneys was almost double for those from DCDD donors as opposed to DBD, with minimal warm ischemia at the time of procurement [6].

Pharmacological prevention of renal IRI can result in the ability to use some of marginal donor kidneys that normally would be rejected during qualification for transplantation and help to decrease the gap between the numbers of patients on the wait list and the number of donor organs that are able to be transplanted.

\section{Conflicts of Interest}

The authors declare that there are no conflicts of interest regarding the publication of this paper.

\section{Acknowledgments}

This project was supported by the Polish National Science Centre, grant no. UMO-2017/27/B/NZ4/00601.

\section{References}

[1] R. F. Saidi, N. Elias, T. Kawai et al., "Outcome of kidney transplantation using expanded criteria donors and donation after cardiac death kidneys: realities and costs," American Journal of Transplantation, vol. 7, no. 12, pp. 2769-2774, 2007.

[2] W. K. Wu, O. Famure, Y. Li, and S. J. Kim, "Delayed graft function and the risk of acute rejection in the modern era of kidney transplantation," Kidney International, vol. 88, no. 4, pp. 851-858, 2015.

[3] S. G. Yarlagadda, S. G. Coca, R. N. Formica, E. D. Poggio, and C. R. Parikh, "Association between delayed graft function and allograft and patient survival: a systematic review and metaanalysis," Nephrology Dialysis Transplantation, vol. 24, no. 3, pp. 1039-1047, 2009.
[4] B. Schröppel and C. Legendre, "Delayed kidney graft function: from mechanism to translation," Kidney International, vol. 86, no. 2, pp. 251-258, 2014.

[5] S. Kunugi, A. Shimizu, N. Kuwahara et al., "Inhibition of matrix metalloproteinases reduces ischemia-reperfusion acute kidney injury," Laboratory Investigation, vol. 91, no. 2, pp. 170-180, 2011.

[6] M. A. J. Moser, S. Arcand, H.-B. Lin et al., "Protection of the transplant kidney from preservation injury by inhibition of matrix metalloproteinases," PLoS ONE, vol. 11, no. 6, Article ID e0157508, 2016.

[7] H. H. Szeto, S. Liu, Y. Soong, and A. V. Birk, "Improving mitochondrial bioenergetics under ischemic conditions increases warm ischemia tolerance in the kidney," American Journal of Physiology-Renal Physiology, vol. 308, no. 1, pp. F11-F21, 2015.

[8] Z. Cavdar, C. Ural, A. Celik et al., "Protective effects of taurine against renal ischemia/reperfusion injury in rats by inhibition of gelatinases, MMP-2 and MMP-9, and p38 mitogen-activated protein kinase signaling," Biotechnic \& Histochemistry, vol. 92, no. 7, pp. 524-535, 2017.

[9] A. Kezic, F. Thaiss, J. U. Becker, T. Y. Tsui, and M. Bajcetic, "Effects of everolimus on oxidative stress in kidney model of ischemia/reperfusion injury," American Journal of Nephrology, vol. 37, no. 4, pp. 291-301, 2013.

[10] S. A. Hosgood, P. J. Yates, and M. L. Nicholson, "1400W reduces ischemia reperfusion injury in an ex-vivo porcine model of the donation after circulatory death kidney donor," World Journal of Transplantation, vol. 4, no. 4, pp. 299-305, 2014.

[11] A. J. Dare, E. A. Bolton, G. J. Pettigrew, J. A. Bradley, K. SaebParsy, and M. P. Murphy, "Protection against renal ischemiareperfusion injury in vivo by the mitochondria targeted antioxidant MitoQ," Redox Biology, vol. 5, pp. 163-168, 2015.

[12] D. M. Summers, C. J. E. Watson, G. J. Pettigrew et al., "Kidney donation after circulatory death (DCD): state of the art," Kidney International, vol. 88, no. 2, pp. 241-249, 2015.

[13] J. Hellegering, J. Visser, H. J. Kloke et al., "Deleterious influence of prolonged warm ischemia in living donor kidney transplantation," Transplantation Proceedings, vol. 44, no. 5, pp. 1222 1226, 2012.

[14] A. Lepiesza, P. Chudoba, D. Kamińska, A. Pupka, and P. Zaleska, "Methods of reduction of warm ischemic time in kidney transplantation and their role of early and late outcomes," Polimery w Medycynie, vol. 46, no. 1, pp. 71-77, 2016.

[15] A. Debout, Y. Foucher, K. Trébern-Launay et al., "Each additional hour of cold ischemia time significantly increases the risk of graft failure and mortality following renal transplantation," Kidney International, vol. 87, no. 2, pp. 343-349, 2015.

[16] J. A. Van Der Vliet and M. C. Warlé, "The need to reduce cold ischemia time in kidney transplantation," Current Opinion in Organ Transplantation, vol. 18, no. 2, pp. 174-178, 2013.

[17] R. M. Cannon, G. N. Brock, R. N. Garrison, J. W. Smith, M. R. Marvin, and G. A. Franklin, "To pump or not to pump: A comparison of machine perfusion vs cold storage for deceased donor kidney transplantation," Journal of the American College of Surgeons, vol. 216, no. 4, pp. 625-634, 2013.

[18] J. Gill, J. Dong, M. Eng, D. Landsberg, and J. S. Gill, "Pulsatile perfusion reduces the risk of delayed graft function in deceased donor kidney transplants, irrespective of donor type and cold ischemic time," Transplantation, vol. 97, no. 6, pp. 668-674, 2014.

[19] N. Vaziri, R. Thuillier, F. D. Favreau et al., "Analysis of machine perfusion benefits in kidney grafts: a preclinical study, Journal of Translational Medicine, vol. 9, p. 15, 2011. 
[20] J. V. Bonventre and L. Yang, "Cellular pathophysiology of ischemic acute kidney injury," The Journal of Clinical Investigation, vol. 121, no. 11, pp. 4210-4221, 2011.

[21] J. M. McCord, "Oxygen-derived free radicals in postischemic tissue injury," The New England Journal of Medicine, vol. 312, no. 3, pp. 159-163, 1985.

[22] J. L. Zweier, "Free radical generation in human endothelial cells exposed to anoxia and reoxygenation," Transplantation Proceedings, vol. 30, no. 8, pp. 4228-4232, 1998.

[23] W. Jassem, S. V. Fuggle, M. Rela, D. D. H. Koo, and N. D. Heaton, "The role of mitochondria in ischemia/reperfusion injury," Transplantation, vol. 73, no. 4, pp. 493-499, 2002.

[24] M. Boratyńska, D. Kamińska, and O. Mazanowska, "Pathophysiology of ischemia-reperfusion injury in renal transplantation," Advances in Hygiene and Experimental Medicine, vol. 58, pp. 1-8, 2004.

[25] H. Nagase, R. Visse, and G. Murphy, "Structure and function of matrix metalloproteinases and TIMPs," Cardiovascular Research, vol. 69, no. 3, pp. 562-573, 2006.

[26] G. Sawicki, "Intracellular regulation of matrix metalloproteinase-2 activity: new strategies in treatment and protection of heart subjected to oxidative stress," Scientifica, vol. 2013, Article ID 130451, 12 pages, 2013.

[27] F. G. Spinale, M. L. Coker, C. V. Thomas, J. D. Walker, R. Mukherjee, and L. Hebbar, "Time-dependent changes in matrix metalloproteinase activity and expression during the progression of congestive heart failure: relation to ventricular and myocyte function," Circulation Research, vol. 82, no. 4, pp. 482-495, 1998.

[28] A. Y. Strongin, I. Collier, G. Bannikov, B. L. Marmer, G. A. Grant, and G. I. Goldberg, "Mechanism of cell surface activation of $72-\mathrm{kDa}$ type IV collagenase. Isolation of the activated form of the membrane metalloprotease," The Journal of Biological Chemistry, vol. 270, no. 10, pp. 5331-5338, 1995.

[29] R. Visse and H. Nagase, "Matrix metalloproteinases and tissue inhibitors of metalloproteinases: structure, function, and biochemistry," Circulation Research, vol. 92, no. 8, pp. 827-839, 2003.

[30] L. M. Golub, H. M. Lee, M. E. Ryan, W. V. Giannobile, J. Payne, and T. Sorsa, "Tetracyclines inhibit connective tissue breakdown by multiple non-antimicrobial mechanisms," Advances in Dental Research, vol. 12, no. 2, pp. 12-26, 1998.

[31] D. Cejka, D. Losert, and V. Wacheck, "Short interfering RNA (siRNA): tool or therapeutic?" Clinical Science, vol. 110, no. 1 , pp. 47-58, 2006.

[32] Q. Yan, W. Sui, B. Wang, H. Zou, G. Zou, and H. Luo, "Expression of MMP-2 and TIMP-1 in renal tissue of patients with chronic active antibody-mediated renal graft rejection," Diagnostic Pathology, vol. 7, no. 1, p. 141, 2012.

[33] I. Bil-Lula, A. Krzywonos-Zawadzka, J. Sawicka et al., "LNAME improves doxycycline and ML-7 cardioprotection from oxidative stress," Frontiers in Bioscience-Landmark, vol. 23, pp. 298-309, 2018.

[34] A. Bindoli and M. P. Rigobello, "Principles in redox signaling: from chemistry to functional significance," Antioxidants \& Redox Signaling, vol. 18, no. 13, pp. 1557-1593, 2013.

[35] I. M. Clark, T. E. Swingler, C. L. Sampieri, and D. R. Edwards, "The regulation of matrix metalloproteinases and their inhibitors," The International Journal of Biochemistry \& Cell Biology, vol. 40, no. 6-7, pp. 1362-1378, 2008.
[36] P. Devarajan, "Update on mechanisms of ischemic acute kidney injury," Journal of the American Society of Nephrology, vol. 17, no. 6, pp. 1503-1520, 2006.

[37] J. Fert-Bober, R. S. Basran, J. Sawicka, and G. Sawicki, "Effect of duration of ischemia on myocardial proteome in ischemia/reperfusion injury," Proteomics, vol. 8, no. 12, pp. 2543-2555, 2008.

[38] A. Kezic, I. Spasojevic, V. Lezaic, and M. Bajcetic, "Mitochondria-targeted antioxidants: future perspectives in kidney ischemia reperfusion injury," Oxidative Medicine and Cellular Longevity, vol. 2016, Article ID 2950503, 2016.

[39] V. P. Skulachev, V. N. Anisimov, Y. N. Antonenko et al., "An attempt to prevent senescence: a mitochondrial approach," Biochimica et Biophysica Acta, vol. 1787, no. 5, pp. 437-461, 2009.

[40] E. J. Gane, F. Weilert, D. W. Orr et al., "The mitochondriatargeted anti-oxidant mitoquinone decreases liver damage in a phase II study of hepatitis C patients," Liver International: Official Journal of the International Association for the Study of the Liver, vol. 30, no. 7, pp. 1019-1026, 2010.

[41] V. J. Adlam, J. C. Harrison, C. M. Porteous et al., "Targeting an antioxidant to mitochondria decreases cardiac ischemiareperfusion injury," The FASEB Journal, vol. 19, no. 9, pp. 10881095, 2005.

[42] I. Lobb, E. Sonke, G. Aboalsamh, and A. Sener, "Hydrogen sulphide and the kidney: important roles in renal physiology and pathogenesis and treatment of kidney injury and disease," Nitric Oxide: Biology and Chemistry, vol. 46, pp. 55-65, 2015.

[43] A. Sener, K.-C. Tran, J. P. Deng et al., "Carbon monoxide releasing molecules inhibit cell death resulting from renal transplantation related stress," The Journal of Urology, vol. 190, no. 2, pp. 772-778, 2013.

[44] I. Lobb, J. Jiang, D. Lian et al., "Hydrogen sulfide protects renal grafts against prolonged cold ischemia-reperfusion injury via specific mitochondrial actions," American Journal of Transplantation, vol. 17, no. 2, pp. 341-352, 2017.

[45] D. Polewicz, V. J. J. Cadete, A. Doroszko et al., "Ischemia induced peroxynitrite dependent modifications of cardiomyocyte MLC1 increases its degradation by MMP-2 leading to contractile dysfunction," Journal of Cellular and Molecular Medicine, vol. 15, no. 5, pp. 1136-1147, 2011. 


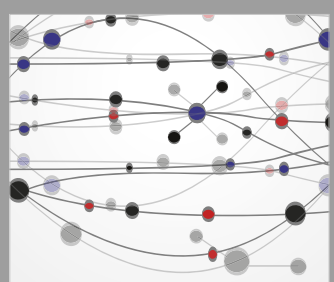

The Scientific World Journal
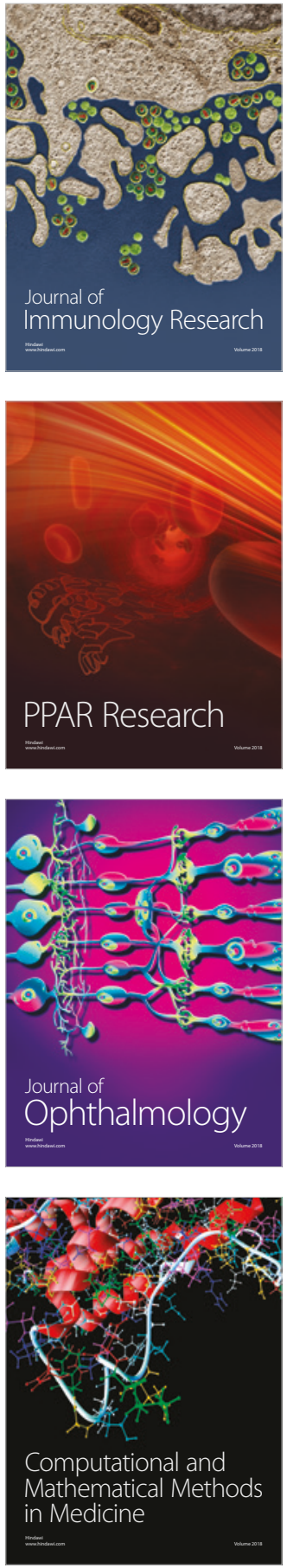

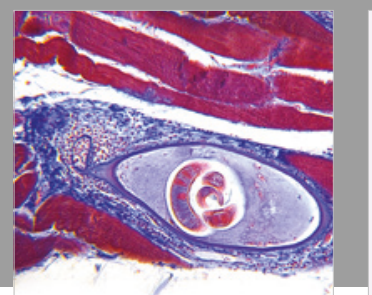

Gastroenterology Research and Practice

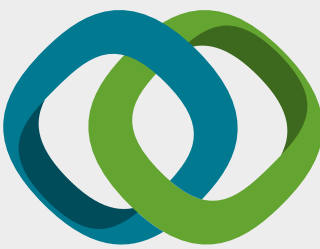

\section{Hindawi}

Submit your manuscripts at

www.hindawi.com
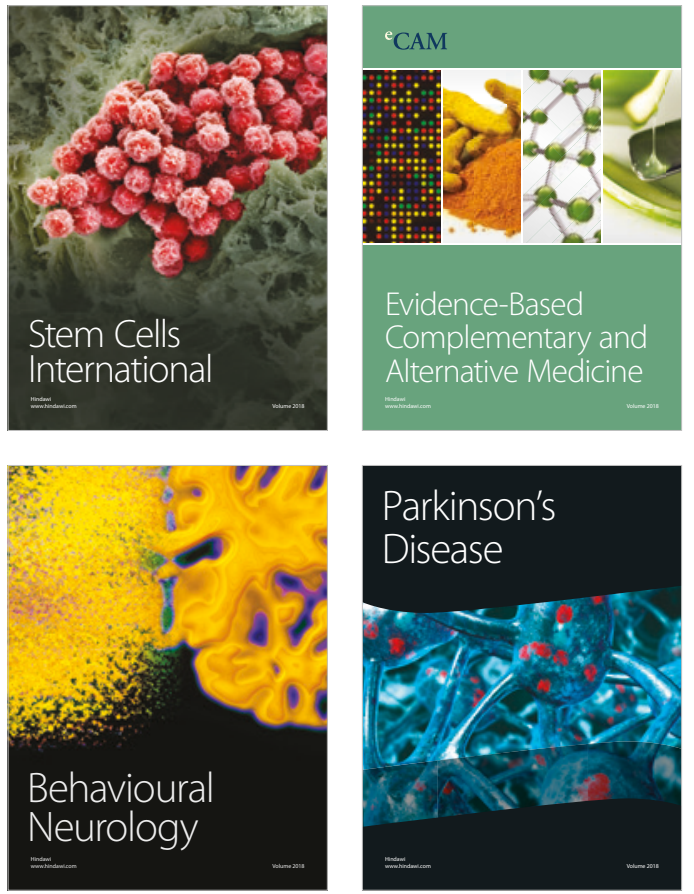

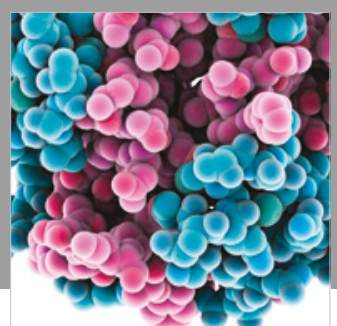

ournal of

Diabetes Research

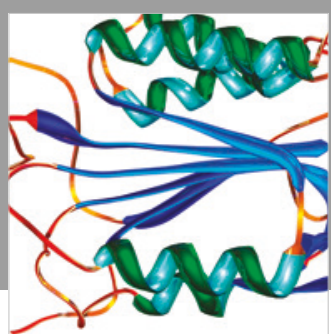

Disease Markers
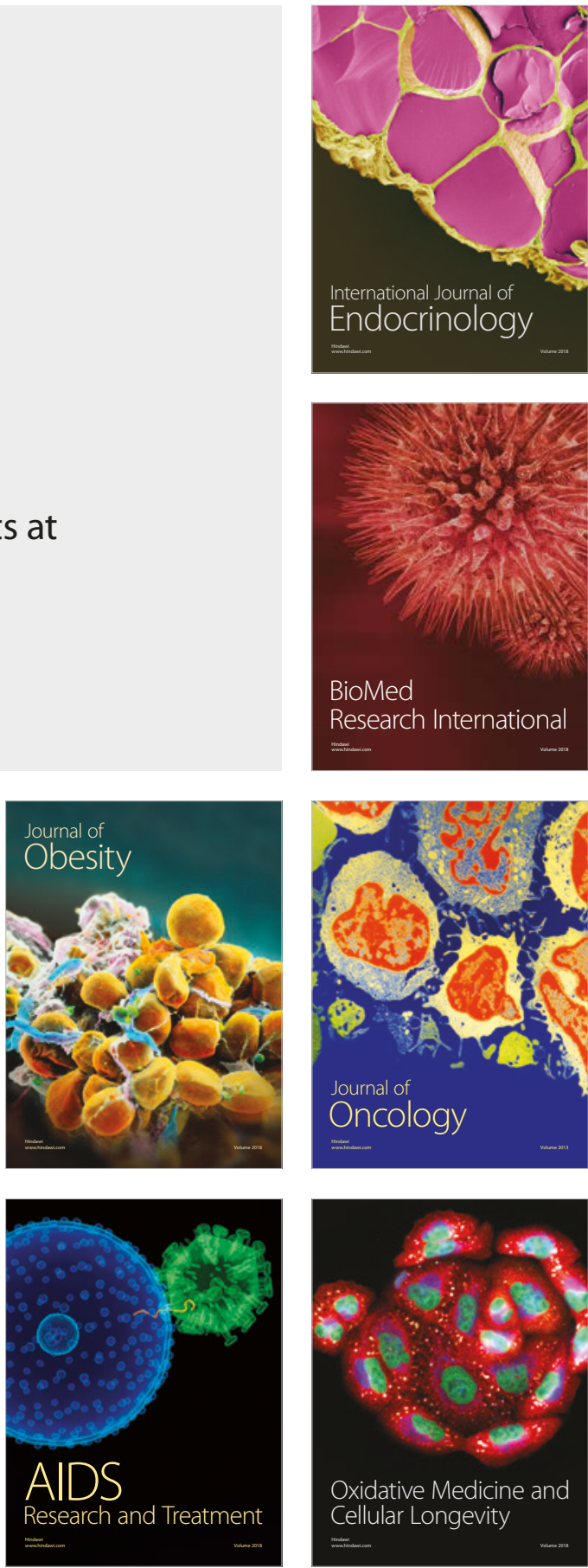